\title{
Ракетно-космічні комплекси
}

https://doi.org/10.15407/knit2019.05.003

УДК 629.788

А. И. Бердник, М. Д. Каляпин, Ю. А. Лысенко, Т. К. Бугаенко

Государственное предприятие «Конструкторское бюро «Южное» им. М. К. Янгеля», Днипро, Украина

МНОГОРАЗОВЫЙ ЛУННЫЙ ЛЭНДЕР

Существенно повысить эффективность космического транспорта позволяет применение многоразовых систем, в особенности использующих топливо космического производства, первым источником которого будут полезные ископаемые Луны. Поэтому первоочередным важнейшим звеном будущей инфраструктуры «окололунная орбита - Луна» станет космическая транспортная система, где ключевым элементом будет многоразовый лунный лэндер (МЛЛ), обеспечивающий грузо- и пассажиропоток сообщением «орбита Луны - поверхность Луны» и обратно. В работе приведены сценарии применения МЛЛ для различных этапов его создания, перечислены основные требования для его разработки. Показана конструкция многоразового лэндера и состав его основных технических систем. Его двигательная установка будет работать на топливе, производимом на лунной базе из местных ресурсов, а бортовые системы будут оптимизированы для многоразового использования и универсальности применения, в частности в вариантах для доставки грузов и ротации экипажей базы. Приведены основные характеристики и энергетические возможности МЛЛ, состав транспортной системы и лунной инфраструктуры, применяемых совместно с МЛЛ. В статье также приводится предварительный анализ экономической эффективности использования многоразового лунного лэндера по сравнению с одноразовыми, а также дальнейшие перспективы его применения.

Ключевые слова: лунная база, многоразовый лунный лэндер.

\section{ВВЕДЕНИЕ}

В рамках работ по концептуальному проекту лунной промышленно-исследовательской базы, разработанному специалистами Конструкторского бюро «Южное» $[1,3]$, одной из ключевых задач являлась разработка технологий добычи и использования местных (лунных) ресурсов, в настояшее время называемых ISRU-технологиями. Использование местных ресурсов обеспечит существенное снижение затрат на космическую деятельность благодаря сокращению массы запускаемых в космос грузов, что составляет львиную долю затрат в космических операциях и является основной сдерживающей силой развития космонавтики за пределы низких околоземных орбит.

( ) А. И. БЕРДНИК, М. Д. КАЛЯПИН,

Ю. А. ЛЫСЕНКО, Т. К. БУГАЕНКО, 2019
В рамках работ, проводимых на лунной базе, планируется создавать и совершенствовать на практике необходимые технологии, а также вводить в строй первые очереди промышленной добычи внеземных ресурсов, куда кроме топлива входят кислород, конструкционные и расходные материалы, редкоземельные элементы и другие ценные ресурсы, применимые как в космосе, так и на Земле.

Самым востребованным в космосе ресурсом будет топливо или рабочее тело ракетных двигателей, причем максимально эффективное его применение будет реализовано на транспортных участках, наиболее близких к месту производства самого топлива, то есть на перелетах между лунной базой, где топливо производится, и лунной орбитальной платформой - ближайшем хабе (перевалочном пункте) транспортной 
цепочки «Земля - Луна». Таким образом, сформирована цель создания многоразового лунного лэндера как первичного потребителя, для которого организация производства топлива на Луне будет необходима в первую очередь.

\section{СПИСОК СОКРАШЕНИЙ}

КА - космический аппарат

ЛБ - лунная база

ЛОП - лунная орбитальная платформа

МЛЛ - многоразовый лунный лэндер

НИИТ - Научно-исследовательский институт технологий

ОКБ - окололунный космический буксир

ПГ - полезный груз

РБ - разгонный блок

УСМ - универсальный стыковочный механизм

ISRU - in-situ resource utilization (использование местных ресурсов)

\section{КОНЦЕПЦИЯ МНОГОРАЗОВОГО ЛУННОГО ЛЭНДЕРА}

Исходя из развития транспортного сообщения с поверхностью Луны, рассмотренного в работе [3] на этапах 3-4, для отработки компонентов многоразового лунного лэндера (МЛЛ) и повышения его надежности предполагается, что на этапе до организации топлива на Луне МЛЛ будет проходить этап летных испытаний и начальной эксплуатации, базируясь на лунной орбитальной платформе, и дозаправляться от топлива, доставляемого с Земли. На данном этапе может также применяться одноразовая версия лэндера, которая не требует дозаправки и обслуживания и является полностью независимой от какой-либо дополнительной инфраструктуры.

Основной типовой миссией МЛЛ выбрана доставка одиночного полезного груза (ПГ) с окололунной орбиты на лунную базу и возвращение лэндера без груза на орбиту, при этом начальная масса аппарата с ПГ на окололунной орбите составляет 20 т, как и в транспортной системе для создания лунной базы [1]. Это упростит переключение с одноразового лэндера начального этапа на многоразовый на дальнейших этапах обслуживания и расширения базы.

Данная транспортная задача является определяющей для формирования основных требова- ний и основных характеристик МЛЛ. Для расширения его функциональности и увеличения эффективности использования рассмотрены также миссии с доставкой на поверхность Луны пилотируемой кабины с экипажем и возвращения ее на окололунную орбиту, что может применяться как для ротации экипажей, так и для пилотируемых высадок в неисследованные районы Луны.

Кроме этого, при оптимизации конструкции МЛЛ учитывались следующие требования:

- компактность, в частности ширина, позволяющая размещение в обтекателе с наружным диаметром 6.2 м ракеты-носителя сверхтяжелого класса;

- минимальная высота верхней платформы с полезным грузом для упрощения погрузочно-разгрузочных операций;

- максимальная конструктивная простота, предполагающая минимальное количество компонентов, и минимум затрат как при создании МЛЛ, так и при его производстве и эксплуатации;

- симметричное размещение топливных баков и полезного груза для минимизации смещения центровки в полете;

- минимальная конечная масса МЛЛ за счет оптимизации силовой конструкции с учетом рационального размещения всех компонентов МЛЛ и оптимального распределения нагрузок на разных режимах полета и посадки.

Следуя данным требованиям, многоразовый лунный лэндер выполнен одноступенчатым, при этом запас топлива в его баках обеспечивает выполнение как целевой транспортной миссии, так и возвращения аппарата к месту базирования - на лунную орбитальную платформу (ЛОП), а впоследствии - на лунную базу (ЛБ), производящую топливо для дозаправок.

Двигатели лэндера работают на жидких кислороде и водороде, получаемых из лунных запасов воды методом электролиза, и обеспечивающих высокую эффективность использования МЛЛ в транспортных миссиях. Как показали проведенные расчеты, аппарат способен доставлять на лунную базу ПГ такой же массы, как и одноразовая система начального этапа, использующая высококипящие компоненты топлива. 


\section{СЦЕНАРИИ ПРИМЕНЕНИЯ МНОГОРАЗОВОГО ЛУННОГО ЛЭНДЕРА}

На рис. 1-3 показана последовательность операций при использовании МЛЛ до начала производства топлива на Луне. Для первой миссии аппарат доставляется с Земли на окололунную орбиту, выполняет посадку на Луну, разгрузку и перелет на лунную орбитальную платформу (рис. 1). Для обеспечения новой миссии с Земли к ЛОП доставляется очередной груз массой 20 т, включающий 8 т груза для доставки на поверхность Луны (либо герметичную кабину массой 3.5 т) и 9 т топлива для дозаправки МЛЛ (рис. 2).

Лэндер дозаправляется, пристыковывается к новому блоку доставляемого груза и после прохождения необходимых тестов начинает новую миссию по доставке на лунную поверхность полезного груза (рис. 3). Цикл (действия, показанные на рис. 2 и 3) повторяется для каждой последующей миссии.

Миссии с пилотируемой лунной кабиной выполняются аналогичным образом, отличие только в отсутствии разгрузки и способе доставки целевого груза - экипаж, доставляемый на Луну, прилетает к ЛОП на отдельном пилотируемом корабле (например «Orion»), а герметичная кабина для лунных высадок используется многократно и базируется на ЛОП. Примечательно, что на данном этапе благодаря базированию на ЛОП, размещаемой на полярной орбите, лэндер может высаживаться практически в любой точке лунного шара (где это позволит рельеф) и возвращаться обратно на ЛОП.

На этапе использования для дозаправки и подготовки МЛЛ лунных ресурсов его базирование переносится на поверхность Луны вблизи лунной базы, где имеются посадочная площадка, а также комплекс дозаправки и предполетной проверки лэндера с необходимым оборудованием. При этом для доставки на поверхность Луны целевого полезного груза уже не потребуется доставлять на окололунную орбиту дополнительные расходуемые грузы (топливо и газы).

Таким образом, в зависимости от этапа эксплуатации и конфигурации лэндера рассмотрено шесть основных сценариев применения МЛЛ три грузовых и три пилотируемых (см. таблицу). Приведенная масса полезного груза определена на основании баллистических расчетов, для которых было разработано отдельное программно-математическое обеспечение.

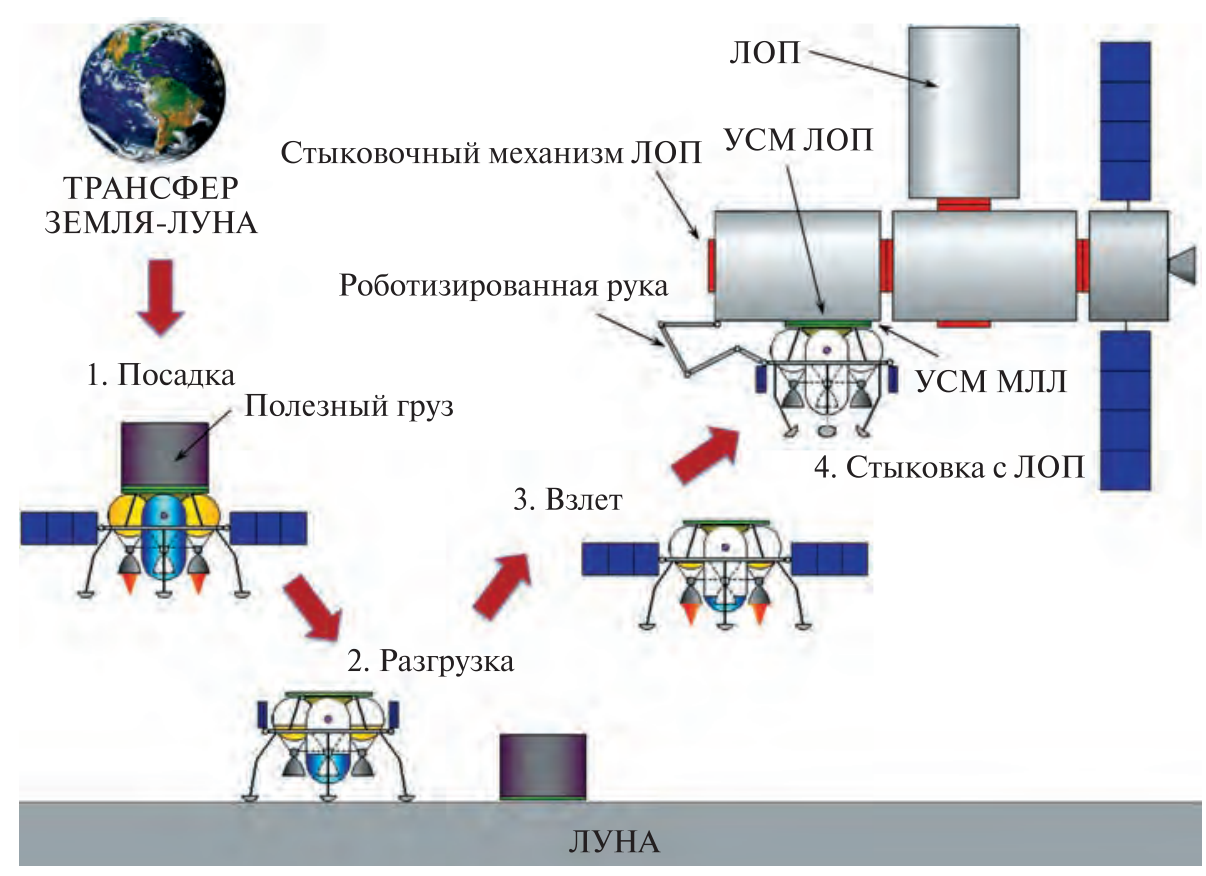

Puc. 1. Первая миссия многоразового лунного лэндера 


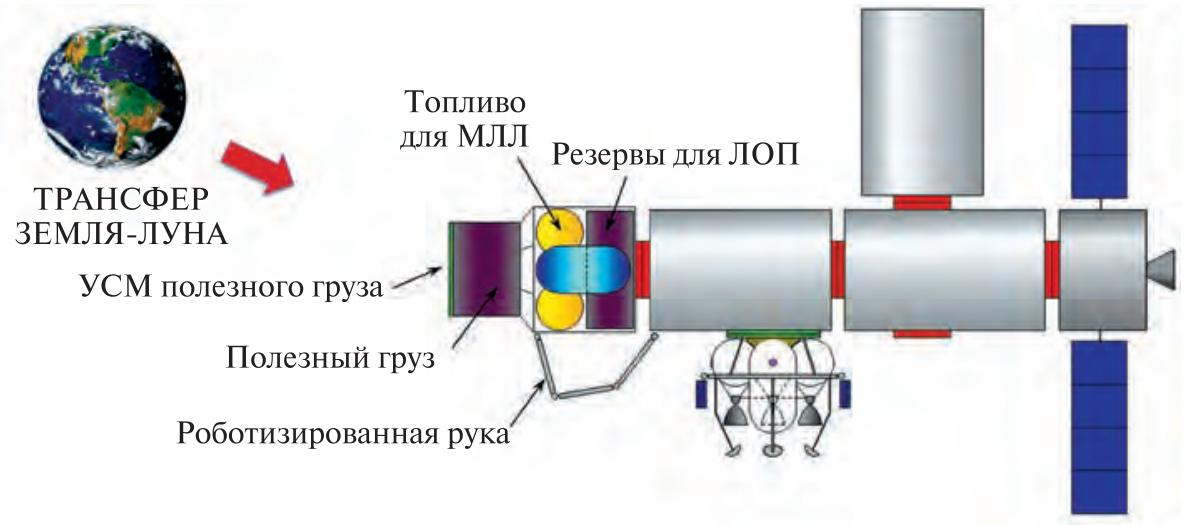

\section{ЛУНА}

Puc. 2. Доставка на лунную орбитальную платформу грузов, необходимых для повторной миссии многоразового лунного лэндера

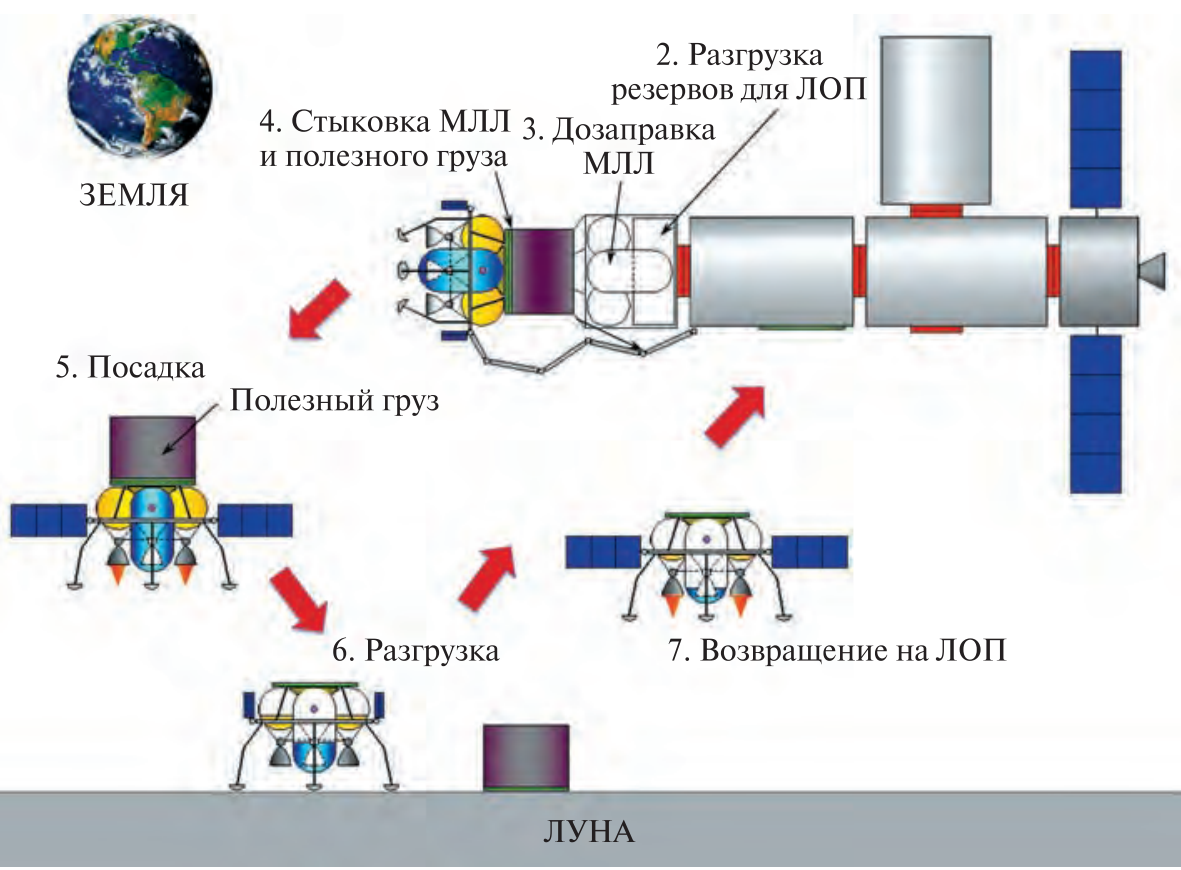

Puc. 3. Подготовка многоразового лунного лэндера на лунную орбитальную платформу и выполнение повторной миссии

Как видно из таблицы, благодаря высокой эффективности кислородно-водородных двигателей даже на начальном этапе МЛЛ будет эффективнее одноразового лэндера на высоко- кипящих компонентах, поскольку в одноразовых миссиях масса груза может быть увеличена до 9.6 т (за счет недозаправки баков при полете в одну сторону). При реализации миссий с много- 
разовым лэндером необходимая для повторной миссии доставка груза на окололунную станцию сокращается до 17 т, поскольку сам лэндер будет использоваться повторно. В пилотируемом варианте с многоразовой кабиной доставка необходимых грузов составит только 9 т топлива и экипаж, прилетающий отдельной миссией на корабле для возврата на Землю, который будет ожидать на окололунной станции. Резерв массы ПГ (3 или 11 т) может использоваться для дооснащения ЛОП новыми модулями, оборудованием, расходными материалами и т. п.

\section{СОСТАВ И ОСНОВНЫЕ ХАРАКТЕРИСТИКИ МНОГОРАЗОВОГО ЛУННОГО ЛЭНДЕРА}

Облик и основные компоненты системы МЛЛ приведены на рис. 4.

Для двигателей МЛЛ была выбрана относительно простая и надежная открытая турбонасосная схема работы с восстановительным газогенератором. В состав двигательной установки лэндера входит три маршевых двигателя, но на финальном участке посадки используется только один центральный, с возможностью регулирования тяги в пределах 50...100 \%. Данная схема обладает повышенной надежностью (возможно аварийное продолжение полета при отказе одного двигателя), меньшим требуемым уровнем тяги и диапазоном дросселирования для единичного двигателя, что сокращает затраты на его создание.
При выборе конструкции МЛЛ анализировались шесть различных вариантов компоновки топливных баков, включающих различное количество сферических, сфероцилиндрических и тороцилиндрических баков. Оптимизированная конструкция МЛЛ включает в себя два сферических бака жидкого кислорода и два сфероцилиндрических бака жидкого водорода с симметричным расположением. Баки соединены в общую конструкцию путем установки на силовой каркас, в верхней части которого установлено универсальное стыковочное устройство. На данном устройстве могут быть установлены как герметичная кабина для пилотируемых миссий, так и различные варианты грузов, отдельные модули будущей лунной базы либо негерметичные платформы с оборудованием, в частности для развертывания добычи лунного льда и производства из него топлива.

Снизу на аппарате установлены четыре раскладывающиеся посадочные опоры, оснащенные механическими демпферами многоразового действия. С их помощью можно обеспечить наклон корпуса МЛЛ после посадки на небольшой угол для упрощения разгрузочных операций. В состав многоразового лэндера входят также блоки двигателей малой тяги, работающие на газообразных компонентах топлива из основных баков. Для обеспечения теплового режима компонентов топлива, а также испарения части топлива

Массовые характеристики и энергетические возможности многоразового лунного лэндера для различных сценариев

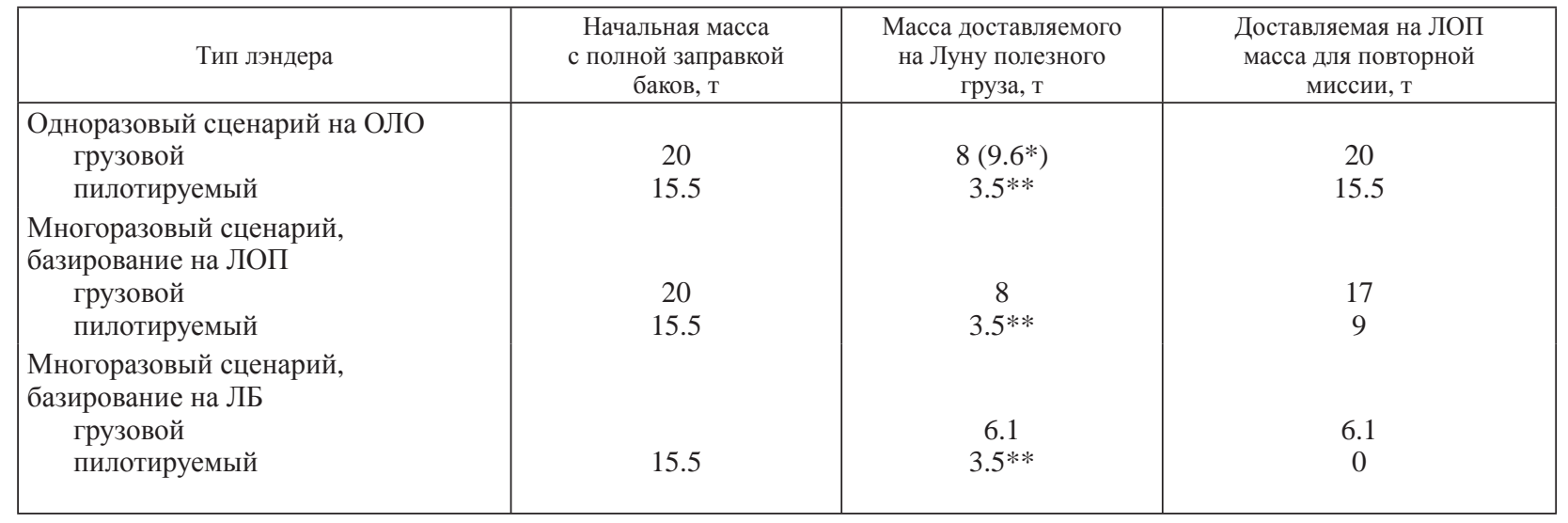

Примечание: * - в скобках указана масса, доставляемая в случае недозаправки баков; ** - для пилотируемых лэндеров в качестве ПГ указана масса пилотируемой кабины с экипажем и попутными грузами. При сокращении данной массы до 3.2 т возможна доставка с ЛОП на ЛБ дополнительного груза массой около 600 кг. 


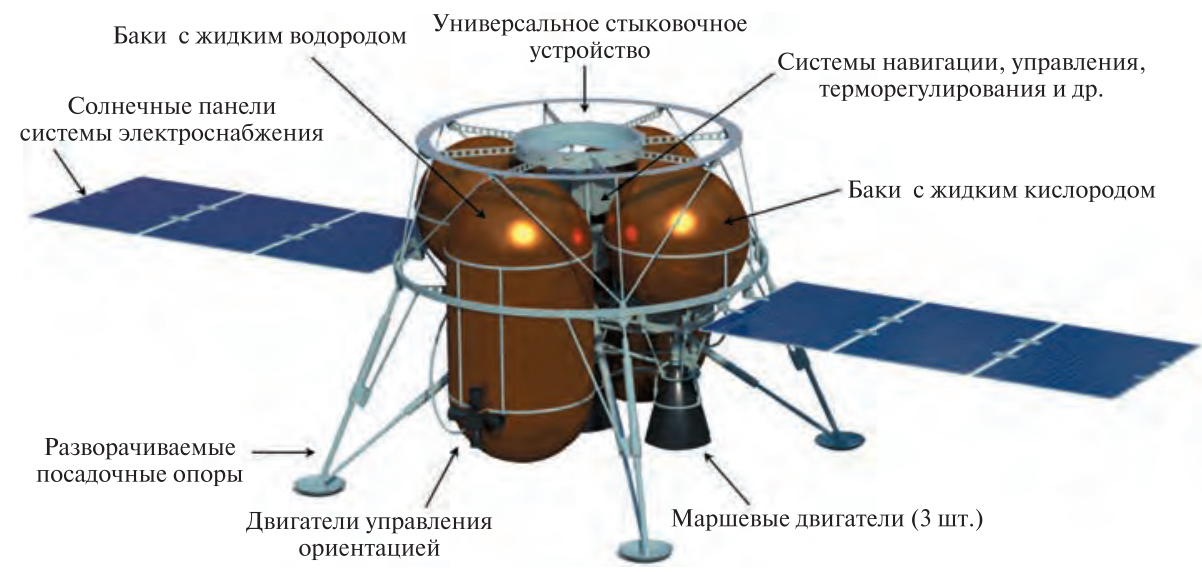

Puc. 4. Многоразовый лунный лэндер

для двигателей малой тяги, предполагается использование бортовой активной криосистемы. Прототипом такой системы может рассматриваться система термостатирования бака с переохлажденным жидким кислородом двигательной установки орбитального корабля многоразовой космической системы «Энергия - Буран» [2], в создании которой принимали участие украинские предприятия, в частности Научно-исследовательский институт технологий «Криогенмаш» (г. Одесса).

В состав бортовой авионики входят системы управления, телеметрии, дальней связи, астронавигации, терморегулирования, приборы системы посадки, и т. д. Система электропитания включает в себя бортовые аккумуляторные батареи и раскладываемые солнечные панели. Основная часть конструкции МЛЛ снаружи покрыта экранно-вакуумной теплоизоляцией. На наружной поверхности МЛЛ также расположены заправочные и контрольно-проверочные интерфейсы, радиаторы, приборы астронавигации и мягкой посадки, антенны космической связи и др.

В архитектуру построения систем МЛЛ закладывается принцип модульности и ремонтопригодности в открытом космосе, что позволит при необходимости выполнить замену отказавшего модуля или другой вид ремонта либо с помощью манипулятора, либо с непосредственным участием экипажа.

Ниже приведены основные характеристики многоразового лэндера.
Основные характеристики многоразового лунного лэндера

Максимальная масса лэндера с ПГ

при доставке к ЛОП, т . . . . . . . . . . . . . 20

Заправленная масса лэндера без ПГ, т . . . . 12

Конечная масса лэндера, т . . . . . . . . . . 3

Масса расходуемого в полете топлива, т . . . 9

Компоненты топлива . ............. LOX+LH

Максимальная тяга маршевых двигателей, кН 79.43 (3 шт.)

Минимальная тяга маршевых двигателей, кН 12.75 (1 шт.)

Удельный импульс маршевых двигателей, м/с 4315

Максимальный диаметр МЛЛ

под обтекателем, м . . . . . . . . . . . . . 5.35

Масса герметичной кабины экипажа, т . . . . 3.2...3.5

Вместимость герметичной кабины, чел. . . . . 4

Полетный ресурс, миссий с возвращением . . 10...20

Как видно, максимальная масса аппарата с ПГ составляет 20 т, внешний диаметр 5.35 м, что соответствует возможностям космической транспортной системы, разработанной для проекта лунной базы [1].

В данную систему входят сверхтяжелая ракета-носитель «Маяк-СТ5», разгонный блок и окололунный космический буксир, при этом РН «Маяк-СТ5» обеспечивает выведение сборки РБ + ОКБ + МЛЛ на низкую околоземную орбиту, а РБ и ОКБ - выход на транслунную и целевую окололунную орбиты соответственно. В перспективе предполагается заменить эти два блока одним кислородно-водородным, обеспечивающим, помимо других задач, доставку на ЛОП топлива для дозаправки МЛЛ непосредственно в своих основных баках. Совместно с возможно- 
стями ЛОП данные компоненты составят единую универсальную транспортную систему, обеспечивающую транспортные операции лунной базы на этапе перехода на производство топлива из лунных запасов воды.

\section{ПРЕИМУЩЕСТВА МНОГОРАЗОВОГО ЛУННОГО ЛЭНДЕРА}

Таким образом, использование в составе лунной транспортной системы многоразового лэндера позволит существенно сократить затраты на доставку полезного груза на Луну за счет исключения необходимости изготовления нового лэндера для каждой миссии, а также за счет сокращения общей массы запускаемого с Земли груза, необходимого для доставки каждой тонны груза на Луну. На первом этапе (базирование на ЛОП) применение МЛЛ сокращает массу необходимого для последующих миссий груза на $25 \%$ для беспилотных рейсов и на $42 \%$ для пилотируемых, что обеспечит существенный экономический эффект с учетом высокой стоимости доставки грузов на окололунную орбиту. На втором этапе, при использовании топлива лунного производства, дополнительный груз для каждой тонны доставляемого с ЛОП на Луну ПГ сокращается практически до нуля, поскольку данная операция выполняется на лунном топливе и с использованием МЛЛ лунного базирования, работоспособность которого обеспечивается только лунной инфраструктурой.

Дальнейшие существенные экономические преимущества могут быть получены за счет доставки в хранилище ЛОП лунного топлива (до 8 т за один рейс) и его использования для дозаправки КА, работающих в окололунном и околоземном пространстве. Такими КА могут быть различные спутники Земли, межорбитальные буксиры, сервисные космические модули, обслуживающие геостационарные КА, уборщики космического мусора, а в перспективе - крупнотоннажные межпланетные корабли пилотируемых экспедиций в пределах всей Солнечной системы. Также планируется доставка различных лунных конструкционных материалов для космического строительства, вплоть до геостационарной орбиты, что будет дешевле, чем привозить их с Земли.
Сам факт наличия регулярно действующей транспортной системы на участке «орбита Луны поверхность Луны» открывает много новых возможностей по развитию формируемых в настоящее время лунного бизнеса и новых рынков, вплоть до космического туризма и создания долговременных лунных поселений или частных лунных баз.

Благодаря использованию лунной инфраструктуры, обеспечивающей регулярные перелеты МЛЛ топливом и межполетным обслуживанием, данная транспортная система способна работать почти автономно, не требуя доставок дополнительной массы грузов для каждого рейса. Это обеспечивает минимальный уровень затрат на доступ к поверхности Луны и полностью соответствует концепции возвращения на Луну для постоянного присутствия [4], сформулированной нынешним главой NASA Джимом Бранденстайном: «Иметь возможность летать туда и обратно с Луны и приземляться в любом месте на ее поверхности и в любое время».

\section{ЛИТЕРАТУРА}

1. Дегтярев А. В., Лысенко Ю. А., Каляпин М. Д., Осиновый Г. Г. Лунная промышленная база. Ключевые шаги для ее создания. Заново открывая космос: Сб. ст. 15-й Междунар. конф., RISpace-2017 Proceedings. 2017.

2. Лукашевич В. П. Орбитальный корабль «Буран». Объединенная двигательная установка (ОДУ). 1998. URL: http://www.buran.ru/htm/odu.htm (дата звернення: 05.07.2019).

3. Лысенко Ю. А., Каляпин М. Д., Осиновый Г. Г., Дегтярев А. В. Концепция лунной промышленно-исследовательской базы. GLEX-2017: Сб. ст. Глобальной конференции по космическим исследованиям. 2017.

4. Grey Hautaluoma Challenging ourselves to create the next generation of lunar explorers. URL: https://www.nasa.gov/ feature/challenging-ourselves-to-create-the-next-generation-of-lunar-explorers (Last accessed: 05.07.2019).

Стаття надійшла до редакиії 05.07.2019

\section{REFERENCES}

1. Degtyarev O. V., Lysenko Y. O., Kaliapin M. D., Osinovyy G. G. (2017). Lunar Industry Base. Stepping Stones for Its Development. Proceedings from 15th Reinventing Space Conference. Glasgow, Scotland. 
2. Lukashevich V. P. (1998). Orbital Ship Buran. Integrated Propulsion Sustem. URL: http://www.buran.ru/ htm/ odu.htm (Last accessed: 05.07.2019).

3. Lysenko Y. O. Kaliapin M. D., Osinovyy G. G., Degtyarev O. V. (2017). Lunar Industry and Research Base Concept. Proceedings from Global Space Exploration Conference GLEX-2017, Beijing, China.

4. Grey Hautaluoma Challenging ourselves to create the next generation of lunar explorers. URL: https://www. nasa.gov/feature/ challenging-ourselves-to-create-thenext-generation-of-lunar-explorers (Last accessed: 05.07.2019).

Received 05.07.2019

\section{О. І. Бердник, М. Д. Каляпін,} Ю. О. Лисенко, Т. К. Бугаєнко

Державне підприємство «Конструкторське бюро «Південне ім. М. К. Янгеля», Дніпро, Україна

\section{БАГАТОРАЗОВИЙ МІСЯЧНИЙ ЛЕНДЕР}

Суттєво збільшити ефективність космічного транспорту дозволяє застосування багаторазових систем, особливо при використанні палива космічного виробництва, першим джерелом якого будуть корисні копалини Місяця. Тому першочерговим найважливішим елементом майбутньої інфраструктури «навколомісячна орбіта - Miсяць» стане космічна транспортна система, в якій ключовим елементом буде багаторазовий місячний лендер (БМЛ), який забезпечує грузо- й пасажиропотік на напрямку «орбіта Місяця - поверхня Місяця» і назад. У роботі наведено сценарії використання БМЛ для різних етапів його створення, перелічено головні вимоги для його розробки. Показана конструкція багаторазового лендера та склад його основних технічних систем. Його рушійна установка буде працювати на паливі, що виробляється на місячній базі з місцевих ресурсів, а бортові системи буде оптимізовано для багаторазового використання та універсальності застосування, зокрема у варіантах для доставки вантажів та ротації екіпажів бази. Наведено основні характеристики та енергетичні можли- вості БМЛ, склад транспортної системи та місячної інфраструктури, що використовується спільно з БМЛ. Зроблено попередній аналіз економічної ефективності використання багаторазового місячного лендера у порівнянні з одноразовими, а також подальші перспективи його застосування.

Ключові слова: місячна база, багаторазовий місячний лендер.

\section{O. I. Berdnyk, Y. O. Lysenko,} M. D. Kaliapin, T. K. Buhaienko

Pivdenne (Yuzhnoye) State Design Office named after M. K. Yangel, Dnipro, Ukraine

\section{REUSABLE LUNAR LANDER}

Application of reusable systems can essentially increase the efficiency of space transportation, especially in case of using a space-manufactured propellant, the first source of which will be the Moon. Therefore, the top-priority and most important chain of future "near-Moon orbit - Moon" infrastructure will become the space transportation system where the key element will be a Reusable Lunar Lander (RLL). It will ensure cargo and passenger traffic from lunar orbit to the Moon surface and back.

The current paper gives scenarios of RLL application for different design stages and specifies the main requirements for its development. The RLL structure is shown, and the composition of its core technical systems is given. Its propulsion unit will work on propellant produced on the lunar base from in-situ resources, and the on-board systems are optimized in terms of reusability and universality of application, in particular, in cases for delivery of cargo and rotation of lunar base crews. The main characteristics and payload capacity of RLL, composition of the transportation system, and lunar infrastructure used together with RLL are given. The paper also shows the preliminary analysis of the economic efficiency of using the reusable lunar lander in comparison with expendable versions and the prospects of its application.

Keywords: lunar base, reusable lunar lander. 